\title{
In Vitro Evaluation of Intra-Aneurysmal, Flow-Diverter-Induced Thrombus Formation: A Feasibility Study
}

\author{
K. Gester, I. Lüchtefeld, M. Büsen, S.J. Sonntag, T. Linde, U. Steinseifer, and (D) G. Cattaneo
}

\begin{abstract}
BACKGROUND AND PURPOSE: Intracranial aneurysm treatment by flow diverters aims at triggering intra-aneurysmal thrombosis. By combining in vitro blood experiments with particle imaging velocimetry measurements, we investigated the time-resolved thrombus formation triggered by flow diverters.

MATERIALS AND METHODS: Two test setups were built, 1 for particle imaging velocimetry and 1 for blood experiments, both generating the same pulsatile flow and including a silicone aneurysm model. Tests without flow diverters and with 2 different flow-diverter sizes (diameter: 4.5 and $4.0 \mathrm{~mm}$ ) were performed. In the blood experiments, the intra-aneurysmal flow was monitored by using Doppler sonography. The experiments were stopped at 3 different changes of the spatial extent of the signal.

RESULTS: No thrombus was detected in the aneurysm model without the flow diverter. Otherwise, thrombi were observed in all aneurysm models with flow diverters. The thrombi grew from the proximal side of the aneurysm neck with fibrin threads connected to the flow diverter and extending across the aneurysm. The thrombus resulting from the 4.0-mm flow diverter grew along the aneurysm wall as a solid and organized thrombus, which correlates with the slower velocities near the wall detected by particle imaging velocimetry. The thrombus that evolved by using the $4.5-\mathrm{mm}$ flow diverter showed no identifiable growing direction. The entire thrombus presumably resulted from stagnation of blood and correlates with the central vortex detected by particle imaging velocimetry.
\end{abstract}

CONCLUSIONS: We showed the feasibility of in vitro investigation of time-resolved thrombus formation in the presence of flow diverters.

ABBREVIATIONS: $F D=$ flow-diverter; PIV = particle imaging velocimetry

ntracranial aneurysm treatment by flow diverters (FDs) aims at blood clotting in the aneurysm, triggered by the reduction or elimination of intra-aneurysmal blood flow. This therapeutic approach offers an alternative treatment for larger wide-neck aneurysms, in which coil embolization is associated with high recurrence. ${ }^{1,2}$ Otherwise, a longer delay to complete intra-aneurysmal thrombosis and documented cases of postprocedural bleeding ${ }^{3-5}$ suggest that the FD-driven mechanism of thrombus formation is

Received December 10, 2014; accepted after revision August 10, 2015.

From the Department of Cardiovascular Engineering (K.G., I.L., M.B., S.J.S., T.L., U.S.), Institute of Applied Medical Engineering, Helmholtz Institute-RWTH Aachen University, Aachen, Germany; and Acandis GmbH \& Co KG (G.C.), Pforzheim, Germany.

This project was funded by the German Federal Ministry for Economic Affairs and Energy.

Please address correspondence to Kathrin Gester, PhD, Department of Cardiovascular Engineering, Institute of Applied Medical Engineering, Helmholtz Institute-RWTH Aachen University, Pauwelsstr 20, D-52074, Aachen, Germany; e-mail: kathrin.gester@rwth-aachen.de

- Indicates open access to non-subscribers at www.ajnr.org

http://dx.doi.org/10.3174/ajnr.A4555 considerably different from that using coils. In previous studies, it has been hypothesized that aneurysm rupture occurring in patients after treatment with FDs is a consequence of uncontrolled flow-driven clot formation resulting in thrombus-associated autolysis ${ }^{4}$ or mural destabilization of the aneurysm wall due to thrombus evolution. ${ }^{6}$

The influence of FDs on hemodynamic properties was investigated in several in vitro experiments by particle imaging velocimetry (PIV). Especially, the influence of the geometry of the aneurysm, ${ }^{7,8}$ the stent porosity, ${ }^{7,9-12}$ the number of stents, and the stent material ${ }^{8,13}$ on intra-aneurysmal velocity fields was extensively studied. All investigations were performed with water-glycerol mixtures as a blood analog fluid. The use of a transparent fluid is inevitable because PIV is an optical method, but it forestalls the possibility of investigate clotting effects. Therefore, because the thrombus-growing process influences the flow behavior, PIV investigations only represent the flow conditions directly after the insertion of FDs.

The goal of our study was the in vitro investigation of time- 

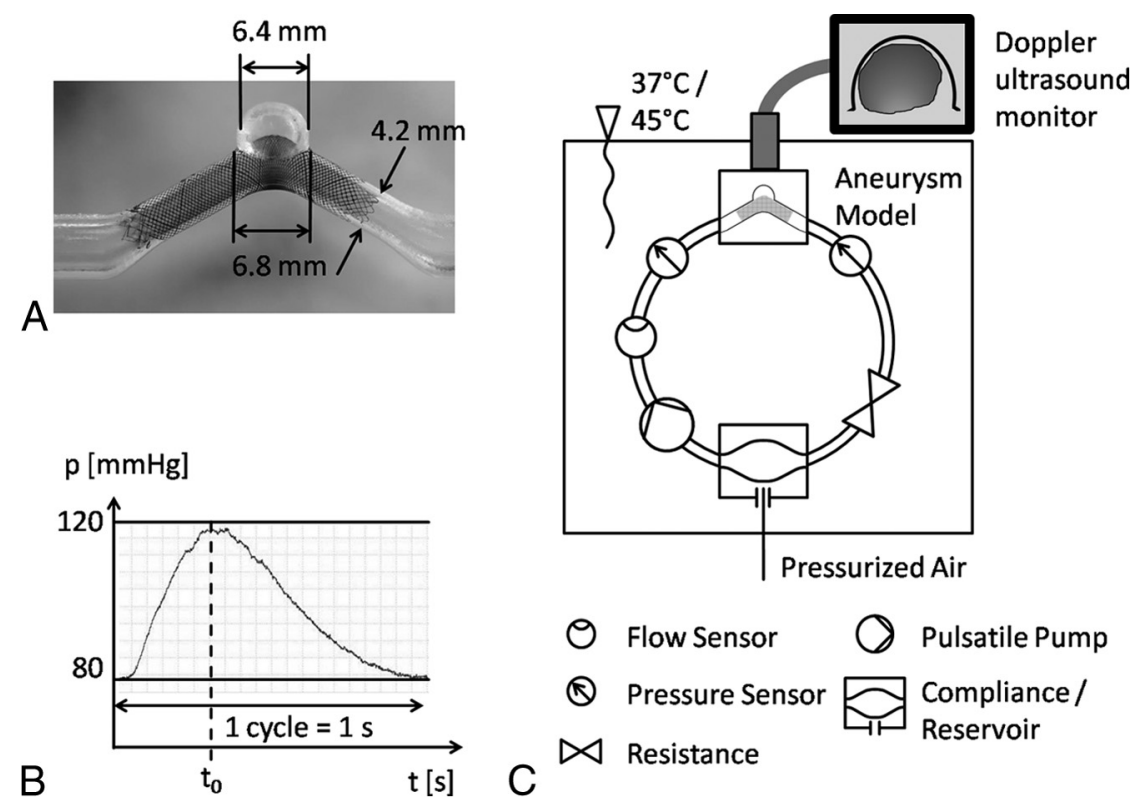

FIG 1. A, Silicone model with an inserted FD. B, Pressure curve upstream of the aneurysm model. C, Flow loop.

resolved formation of thrombi triggered by FDs. Although biologic mechanisms, triggered by the aneurysm wall, are not depicted in the new in vitro model, the location and shape of thrombus during the forming and growing process, as well as the composition of the thrombus, were investigated for 2 different FD configurations. Moreover, we correlated the results with PIV measurements.

\section{MATERIALS AND METHODS}

\section{In Vitro Aneurysm Model and Flow-Loop Setup}

A simplified geometry of a lateral aneurysm was used in this study to limit the geometric variables. The aneurysm was spheric with an inner diameter of $6.4 \mathrm{~mm}$ and an oval neck of $6.8 \times 5.4 \mathrm{~mm}$. These dimensions are in agreement with those in the clinical literature. ${ }^{14}$ The parent vessel had an inner diameter of $4.2 \mathrm{~mm}$ with an angle of $120^{\circ}$ at the aneurysm neck (Fig $1 A$ ). The aneurysm models were blocks, made from silicone by a casting technique using male casts of the aneurysm model manufactured by rapid prototyping (Objet Eden 350V; Stratasys, Eden Prairie, Minnesota). We used 2 different kinds of silicone: Elastosil RT 601 (Wacker Chemie, Munich, Germany) for PIV measurements due to opacity requirements and Elastosil RT 625 (Wacker Chemie) for blood experiments due to hemocompatibility. For all models, the FD Derivo Embolization Device (Acandis GmbH \& Co. KG, Pforzheim, Germany) with inner diameters of 4.5 and $4.0 \mathrm{~mm}$ (called FD-4.5 and FD-4.0) was used. The device is composed of 24 nitinol wires with a diameter of $40 \mu \mathrm{m}$ and an electropolished and annealed surface, characterized by approximately a $50-\mathrm{nm}$ thin layer of oxides and nitrides/oxynitrides. The wires at the distal end of the FD run in loops back to the proximal end, where the wires end openly, resulting in a mesh of $2 \times 24$ wires.

For the PIV measurements, 3 models were used (empty and loaded with FD-4.5 and FD-4.0, respectively). For blood experiments, we used 10 models: 4 empty, 2 loaded with FD-4.5, and 4 loaded with FD-4.0. The FD-4.5 was oversized and axially stretched, which led to an increase of cell size, whereas the FD-4.0 was fitted with an outer diameter of approximately 4.2 $\mathrm{mm}$ within the parent vessel without radial compression. With a braiding angle of $75^{\circ}$ in the completely expanded state, mean porosities within the model were $72 \%$ and $65 \%$ for FD-4.5 and FD-4.0, respectively, according to geometric calculation, whereas manual loading of the devices in the model led to heterogeneities and variability of local porosity. The models were placed in a flow loop, which consisted of a pulsatile-operated blood pump (deltastream DP3; Medos Medizintechnik, Stolberg, Germany) and a compliance/reservoir (Fig 1C). All components were connected by PVC tubing and connectors made of polycarbonate. Pump, compliance pressure, and resistance were adjusted to achieve an average volume flow rate of $\dot{V}=220 \frac{\mathrm{mL}}{\mathrm{min}}$, according to a flow rate between that of the internal carotid artery and the media carotid artery $^{15-17}$ and a pressure curve behind the pump between 80 and $120 \mathrm{~mm} \mathrm{Hg}$, as shown in Fig $1 B$. The average volume flow rate (T110; Transonic Systems, Ithaca, New York) was recorded directly behind the pump; and the pressure curve (SP844; Memscap, Crolles, France) upstream, downstream of the aneurysm model, and both was accordingly adjusted. The intraluminal mean Reynolds number, Womersley number, and pulsatility index as defined in Hoi et al, ${ }^{15}$ were 358, 6.0, and 1.19, respectively. The whole test setup was temperature-controlled at $45^{\circ} \mathrm{C}$ for PIV measurements and $37^{\circ} \mathrm{C}$ for blood experiments.

\section{PIV Measurements}

A PIV system (Dantec Dynamics, Skovlunde Denmark) was added to the test setup described above. The PIV system included an Nd:Ylf laser (Pegasus; NewWave, Fremont, California), a light sheet optic (80X70, Dantec Dynamics, Skovlundet, Denmark), and a CMOS camera $(1280 \times 1024$ pixels, Redlake, X3 mol/LM-4; IDT, Tallahassee, Florida) positioned perpendicular to the laser light sheet and a traverse for microaccurate movement of the whole system.

A mixture of glycerol and distilled water $(55.8 \%-44.2 \%$ by weight) at $45^{\circ} \mathrm{C}$ was used as working fluid. At these parameters, the refractive index matches that of silicone $\left(\mathrm{n}_{\text {silicone }}=\mathrm{n}_{\text {water/glycerol }} \approx\right.$ 1.404); this avoids distortion of the recorded images. Additionally, the viscosity of this fluid $\left[\eta_{\text {water-glycerol }}=(3.5395 \pm 0.0417) \mathrm{mPas}\right]$ corresponds to that of high sheared blood ( $\left.\eta_{\mathrm{blood}}=3.6 \mathrm{mPas}\right)$, allowing similar flow properties. ${ }^{18}$

Neutrally buoyant polystyrene tracer particles, $10 \mu \mathrm{m}$ in diameter and containing Rhodamine B (MF-RhB-polymer particles; Microparticles, Berlin, Germany), were added to the water-glycerol mixture. The particles were illuminated by a laser light sheet, and particle images were captured with the 

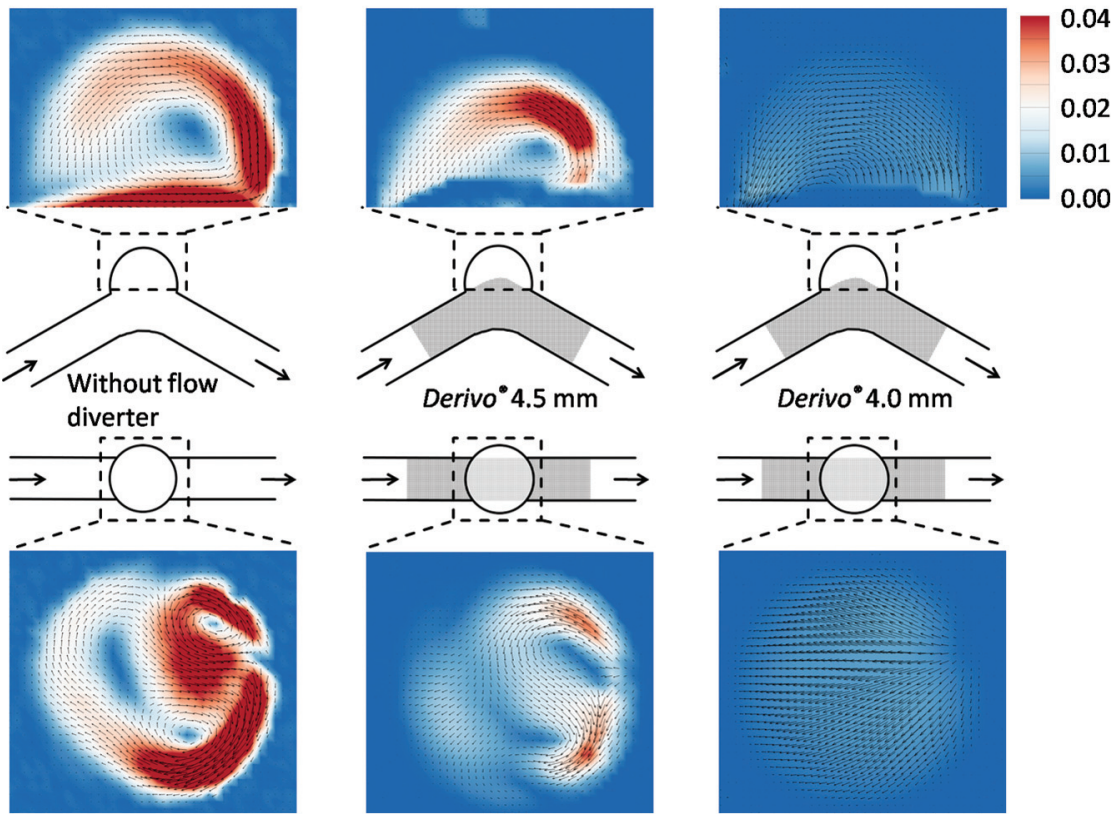

FIG 2. Results of the PIV measurements. The velocity fields for the systolic flow are recorded in the sagittal and transverse planes.

camera. The maximum fluorescence emission wavelength of the tracer particles was $584 \mathrm{~nm}$. With a suitable filter, the laser light with a wavelength of $527 \mathrm{~nm}$ could be filtered to increase image quality. Ten pump cycles were recorded. Measurements without the FD were recorded in "single image mode" with a frequency of $100 \mathrm{~Hz}$, and measurements with the FD in double-image mode with a time difference between the 2 images varied from 100 to $950 \mu$ s. To generate the velocity fields, we divided the recorded images into small areas of interrogation. Using a cross-correlation algorithm, we calculated displacement vectors for each area of interrogation for subsequent images. The resulting vector fields had a resolution of $70 \times 70$ $\mu \mathrm{m}$. They were averaged for the 10 pump cycles by using the software Matlab (MathWorks, Natick, Massachusetts). The velocity fields were recorded in the sagittal and transverse planes of the aneurysm, the last $3.2 \mathrm{~mm}$ below the top of the aneurysm. In this study, we concentrated on the velocity field at the systolic pressure peak, corresponding to time $t_{0}$ of the pressure wave (Fig $1 B)$.

\section{Blood Experiments}

All parts of the test setup were cleaned for 1 hour according to a standardized in-house cleaning procedures with 40\% 2-propanol at room temperature and rinsed with distilled water and saline solution.

The blood was collected from the cervical artery of slaughterhouse pigs. It was immediately anticoagulated with Clexane multidose (Sanofi-Aventis Pharma Deutschland, Frankfurt, Germany) with concentrations of 2000 or 4000 IU/L. Because coagulation activity is very dependent on the blood used, concentration was varied during the study to allow a visualization of thrombus formation in a feasible time window of a maximum duration of 12 hours. However, the influence of the anticoagulant concentration on the thrombus formation was not an aim of this
$\mathrm{V}[\mathrm{m} / \mathrm{s}] \quad$ study, and only the results of experiments with the same anticoagulant concentration were compared. Blood count was determined before and after the blood experiments by using a hematology analyzer (Celltac- $\alpha$ MEK-6450; Nihon Kohden, Tokyo, Japan). Throughout the experiments, the flow in the aneurysm was monitored with the help of a color Doppler sonography system (Vivid I; GE Healthcare, Milwaukee, Wisconsin) by recording changes in the Doppler signal in magnitude and spatial expansion. The sonographic probe was placed on top of the silicone model, allowing monitoring of the whole aneurysm region (Fig $1 C$ ).

To analyze the structure of the FDinduced thrombi at different growing phases, 3 study end points were defined on the basis of the changes in the spatial extent of the signal: 1) beginning, 2) approximately $50 \%$, and 3 ) nearly complete reduction of the spatial extent of the signal. For 2 FD-4.0s, the tests were stopped at the first end point to investigate the early anchoring of the thrombus to the FD. Additionally, FD-4.5 and FD-4.0 were both investigated at the second and third end points to compare the development of the resulting thrombi for different mesh porosities. For the empty models, in which no thrombus formation was expected, 2 end points were defined at 5 and 12 hours after starting the experiment. After we reached each end point, the time was recorded, the blood flow was interrupted, and the aneurysm model was rinsed with $100 \mathrm{~mL}$ of phosphate buffer solution $(\mathrm{pH}=7.4)$, preserved in formaldehyde (4\%) for 24 hours, and dehydrated in ascending concentrations of propanol (30\%, 50\%, 70\%, 90\%, 100\%, 100\%). Finally, the silicone model was opened, and pictures were taken. The thrombi arising at the third end point were taken out and embedded in paraffin; sections were cut (HM 360; Thermo Fisher Scientific, Waltham, Massachusetts) and stained with H\&E for histology.

\section{RESULTS}

\section{PIV Measurements}

The velocity fields for the systolic flow, recorded in the sagittal and transverse planes, are shown in Fig 2. Without the FD, the fluid entered the aneurysm distally and moved along the aneurysm wall until leaving it at the proximal side on the sagittal plane. The velocities at the distal side were higher than those at the proximal side. The area of the slowest velocities was close to the center of the aneurysm, where a vortex occurred. On the transverse plane, the velocity field was irregular. The maximal flow velocity, detected on the transverse plane, was $0.14 \mathrm{~m} / \mathrm{s}$. A similar velocity field on the sagittal plane was observed in the model with FD-4.5. However, the maximum velocities were reduced to $0.04 \mathrm{~m} / \mathrm{s}$. The vortex area with the slowest velocities within the aneurysm was smaller and closer to the parent vessel. In the transverse plane, a 


\begin{tabular}{|c|c|c|c|c|c|c|c|c|}
\hline $\begin{array}{c}\text { Name of } \\
\text { Trial }^{\mathrm{a}}\end{array}$ & FD & $\begin{array}{c}\text { Clexane } \\
\text { Concentration } \\
\text { (IU/L) }\end{array}$ & $\begin{array}{l}\text { Platelet Count, } \\
\text { Start of Trial } \\
\left(10^{3} / \mu \mathrm{L}\right)\end{array}$ & $\begin{array}{l}\text { Platelet Count, } \\
\text { End of Trial } \\
\left(10^{3} / \mu \mathrm{L}\right)\end{array}$ & $\begin{array}{c}\text { Hematocrit } \\
\text { Value, Start of } \\
\text { Trial (\%) }\end{array}$ & $\begin{array}{c}\text { Hematocrit Value, } \\
\text { End of Trial (\%) }\end{array}$ & Duration & $\begin{array}{l}\text { Qualitative } \\
\text { Spatial Extent of } \\
\text { the Doppler } \\
\text { Signal at End of } \\
\text { Trials }^{b}\end{array}$ \\
\hline O-A & None & 2000 & 205 & 220 & 41.3 & 39.5 & $5 \mathrm{~h} 2 \mathrm{~min}$ & \\
\hline O-B & None & 4000 & 220 & 211 & 45.2 & 44.3 & $5 \mathrm{~h} 1 \mathrm{~min}$ & \\
\hline $\mathrm{O}-\mathrm{C}$ & None & 2000 & 212 & 213 & 39.2 & 46.4 & $12 \mathrm{~h} 2 \mathrm{~min}$ & \\
\hline O-D & None & 4000 & 214 & 377 & 41.3 & 15.0 & $12 \mathrm{~h} 4 \mathrm{~min}$ & \\
\hline $4.0-A$ & FD-4.0 & 2000 & 235 & 345 & 42.6 & 20.4 & $4 \mathrm{~h} 9 \mathrm{~min}$ & \\
\hline $4.0-B$ & FD-4.0 & 2000 & 340 & 290 & 38.7 & 40.8 & $11 \mathrm{~h} 58 \mathrm{~min}$ & \\
\hline $4.0-C$ & FD-4.0 & 2000 & 270 & 225 & 38.7 & 40.1 & $3 \mathrm{~h} 4 \mathrm{~min}$ & 101 \\
\hline 4.0-D & FD-4.0 & 4000 & 245 & 250 & 40.1 & 42.1 & $12 \mathrm{~h} 42 \mathrm{~min}$ & \\
\hline $4.5-C$ & FD-4.5 & 2000 & 270 & 355 & 44.2 & 38.0 & 11 h 10 min & (2) \\
\hline 4.5-D & FD-4.5 & 4000 & 265 & 295 & 36.3 & 31.8 & $9 \mathrm{~h} 51 \mathrm{~min}$ & \\
\hline
\end{tabular}

${ }^{a} \mathrm{O}-\mathrm{A}$ and O-B are after 5 hours; O-C and O-D are after 12 hours; 4.0-A and 4.0-B are the first end point; 4.0-C and 4.5-C are the second end point; and 4.0-D and 4.5-D indicate no sonography signal at the end of the trial (third end point).

b The gray area in the aneurysm represents the spatial extent of the Doppler ultrasound signal.
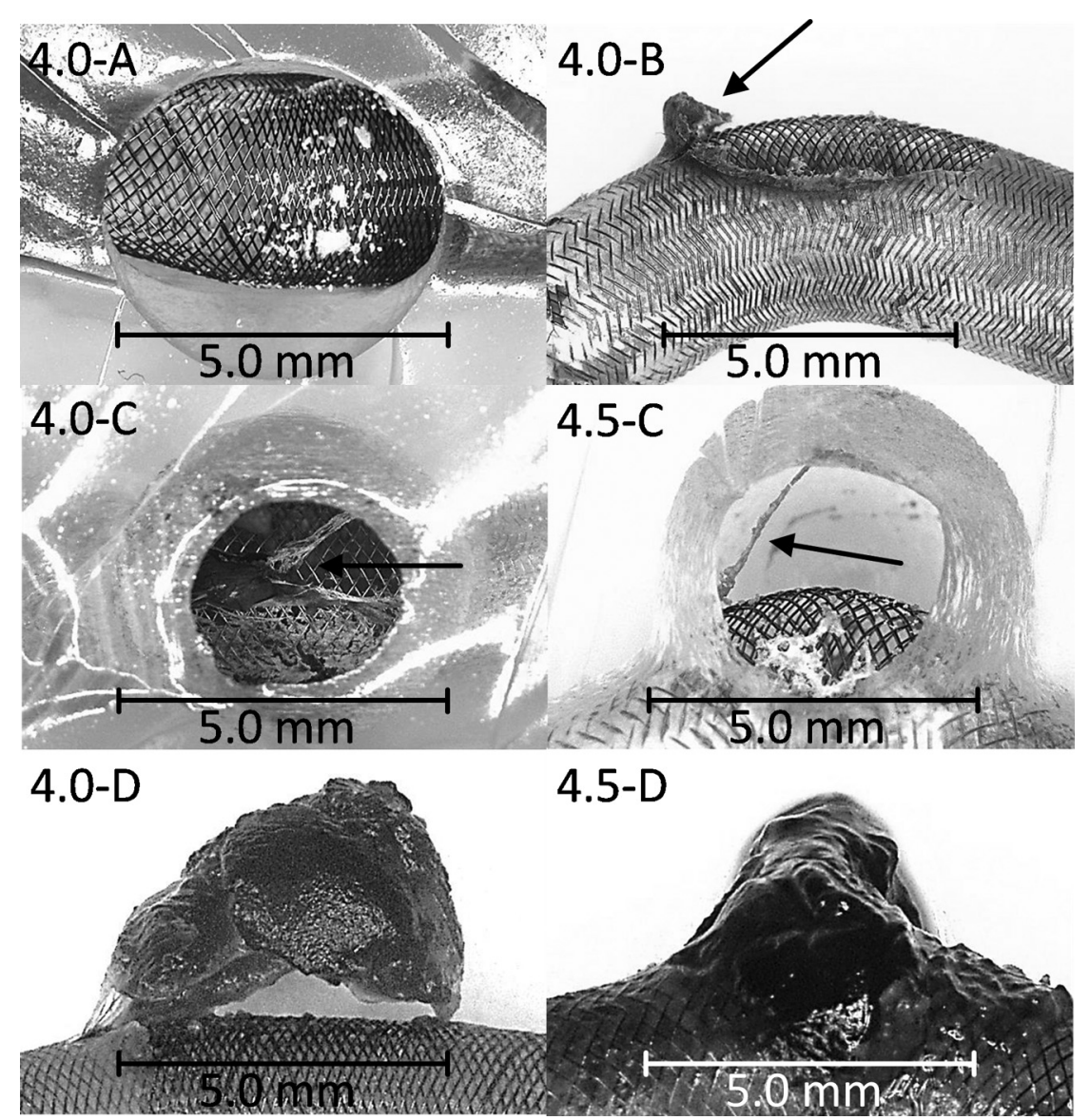

FIG 3. Thrombi after the blood experiments. Experiments 4.0-A and 4.0-B show no thrombus or the beginning of a thrombus; $4.0-\mathrm{C}$ and $4.5-\mathrm{C}$ show a fibrin network, anchored at the proximal side of the aneurysm in the FD and extended across the aneurysm up to the upper distal wall; 4.0-D shows a red cap-shaped thrombus that has fibrin strands connected to the proximal part of the FD; and 4.5-D shows an apparently erythrocyte-rich thrombus with a very soft consistency, which almost completely fills the aneurysm. Degree of magnification: $5 \times$ (left images), $40 \times$ (right images).

very irregular and symmetric velocity field occurred, with a vortex in the distal area of the aneurysm extending across the whole neck width. The FD-4.0 led to a different velocity profile, with the highest velocities appearing symmetric at both distal and proximal sides and closer to the FD compared with both previous models.
In addition, in this model, the fluid entered the aneurysm on the distal side. Furthermore, maximum flow velocities were reduced to $0.005 \mathrm{~m} / \mathrm{s}$. The velocity field in the transverse plane was much more symmetric than that without the FD and with FD-4.5, with significant reduction of the velocities.

\section{Blood Experiments}

An overview of the performed experiments is listed in the Table.

Four models without FDs were tested with anticoagulant concentrations of $2000 \mathrm{IU} / \mathrm{L}$ (O-A, O-C) and 4000 IU/L (O-B, O-D). No signal change was detected, so the blood flow was interrupted at the end points of 5 hours (O-A, O-B) and 12 hours (O-C, O-D). No thrombi were detected after the models were rinsed.

In experiments with the first end point (4.0-A, 4.0-B), either no thrombus or the beginning of a thrombus at the proximal side was found in the neck area (Fig 3). Second end point experiments (4.0-C, 4.5-C) led to a fibrin network, which anchored to the FD at the proximal side of the aneurysm and extended across the aneurysm to the upper distal wall (Fig 3). This was observed for both FDs, whereas it was more pronounced for FD-4.0. When the sonography signal no longer existed (4.0-D, 4.5-D), a red cap-shaped thrombus could be observed for the FD-4.0. The thrombus had fibrin strands connected to the proximal part of the FD (Fig 3) but showed a gap to the rest of the FD surface, which remained patent. In comparison, the thrombus resulting from the FD-4.5 appeared as erythrocyte-rich, which almost completely filled the aneurysm. 


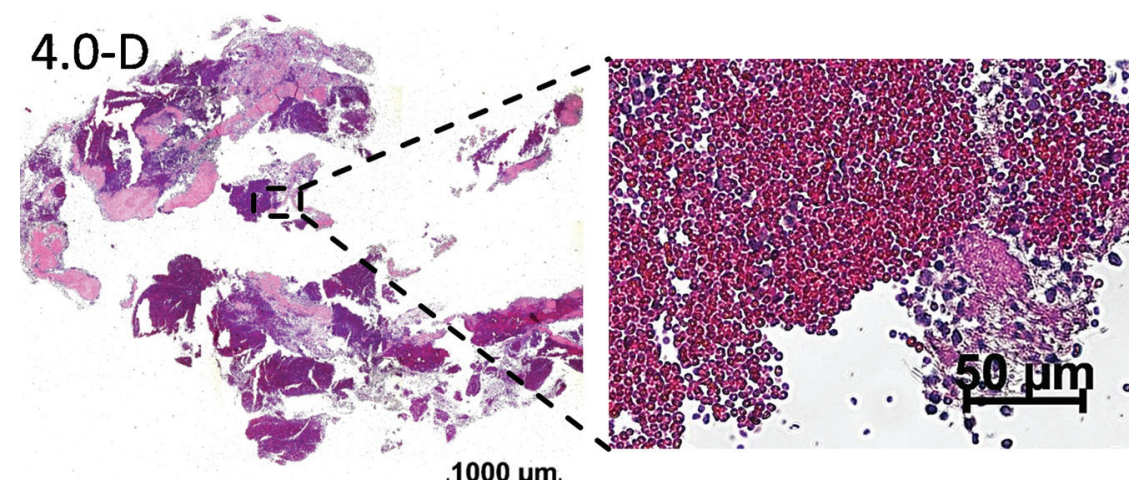

$1000 \mu \mathrm{m}$

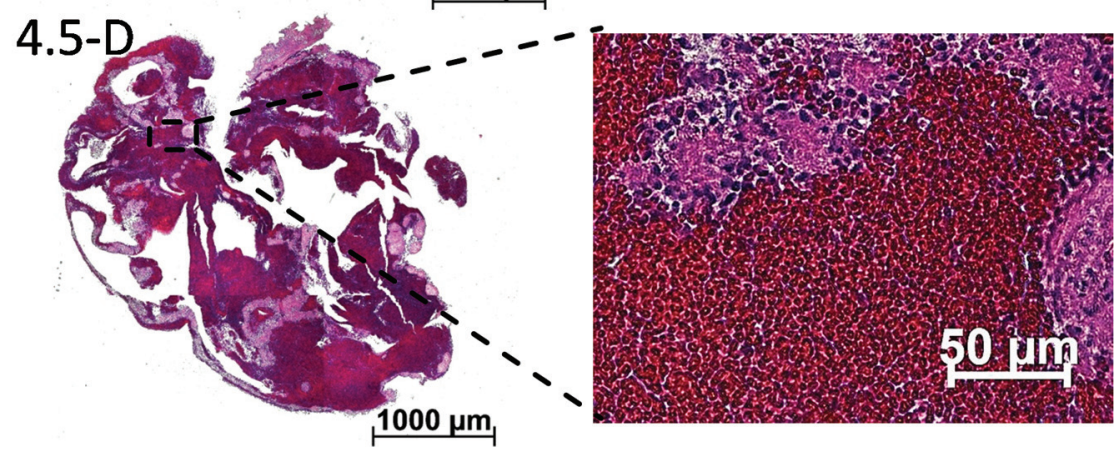

FIG 4. H\&E-stained sections of the thrombi resulting from experiments 4.0-D and 4.5-D. Erythrocyterich areas are stained dark red, whereas fibrin-and platelet-rich areas are stained a light pink. Degree of magnification: $5 \times$ (left images), $40 \times$ (right images).

After we removed the silicone model, the thrombus collapsed because it had a very soft consistency.

The sections of both thrombi showed a similar structure (Fig 4). Fibrin- and platelet-rich areas and erythrocyte-rich areas could be identified and could be clearly distinguished from each other. The sections of the thrombus that developed in the experiment with FD-4.5 showed a larger amount of erythrocyte-rich areas in comparison with the thrombus from FD-4.0. However, even here, fibrin- and platelet-rich areas were clearly visible. In all trials with FDs, a thin layer of thrombi on the FD was observed. Mostly, the thrombi appeared as white, fibrin- and platelet-rich and accumulated partially between the stent struts of the FD; but also red, erythrocyte-rich areas could be found sporadically (4.0-B, 4.0-C).

The blood values (Table) of the individual experiments were within the measurement accuracy of the blood count system and the expected change of blood values in an in vitro experiment. However, in 2 experiments, the hematocrit value dropped noticeably during the experiment (O-D and 4.0-A), and in 3 experiments, the platelet count increased (O-D, 4.0-A, and 4.5-C).

\section{DISCUSSION}

Many in vitro PIV studies investigated the influence of FDs on hemodynamic properties, ${ }^{7-13}$ because this method is established for measuring flow behavior. However, when using a water-glycerol mixture, which is transparent and thus enables PIV measurements, one disregards the thrombus formation and its influence on the flow. Therefore, the PIV measurement only represents the flow conditions directly after the insertion of FDs. Moreover, the influence of the FDs on the thrombus formation was further investigated in animal trials. ${ }^{19-22}$ However, the dynamics of intra- aneurysmal thrombosis cannot be observed in the follow-up period, which takes several weeks, because blood flow cannot be abruptly stopped at defined phases of thrombus formation. In vitro blood experiments allow arbitrarily accelerating thrombus formation by appropriate anticoagulant concentrations so that we can continuously visualize the different phases of formation and abruptly stop the experiment for thrombus observation based on visualization. We combined PIV measurements and in vitro blood experiments monitored by Doppler sonography for the investigation of velocity fields and thrombus formation in silicone aneurysm models.

In the blood experiments, both FDs caused thrombus formation in the aneurysm model in contrast to the experiments with empty aneurysm models. We conjecture that the material triggers the thrombus formation because fibrinand platelet-rich thrombi were present on the FD surface before any thrombus in the aneurysm was observed. Therefore, blood flow could play an important role in the mechanism of thrombus formation because the thrombi prevalently arose at the same side of the FD and developed in a similar direction. Experiments that were stopped at the first end point showed that the thrombi formation begins at the proximal side of the aneurysm neck. Fibrin threads with entangled platelets were connected to both FDs and extended across the aneurysm. We presume a combination of flow- and surface-induced coagulation because the velocities on the proximal side were the slowest and the mesh of the FD is a good anchorage point.

After the FDs were anchored on the proximal side of the aneurysm, the further course of thrombi formation was different for both FDs with different sizes and thus porosity. The thrombus, resulting from the FD-4.0 with lower porosity, grew along the aneurysm wall as a solid and organized thrombus with fibrin and erythrocytes included. The thrombus seemed to develop against flow direction detected by PIV, which was from distal to proximal, in the region with lower and uniform velocities. At the neck of the aneurysm, where velocities were higher in PIV, a small thrombus-free gap was observed. The thrombus that evolved when using the FD- 4.5 showed no identifiable growing direction. The entire thrombus presumably resulted from stagnation of blood after the formation of fibrin through the aneurysm because it was not very stable or very erythrocyte-rich. This finding is supported by the microtome sections, which showed clearly defined fibrin areas and areas of erythrocytes loosely next to each other and correlate with the central vortex detected by PIV.

The noticeable decrease of the hematocrit value and the simultaneous increase in platelet count indicates hemolysis in the circuit. 
The blood count device identifies the individual cell types by their sizes; therefore, cell fragments of destroyed erythrocytes are incorrectly identified as platelets. The hemolysis is probably caused by the pump.

\section{Limitations}

In the PIV test setup, the particles are illuminated by a laser light sheet that has a thickness of approximately $1 \mathrm{~mm}$. Velocity components vertical to that plane are not detected and considered. Furthermore, in this study, only velocity components at the systolic pressure peak were considered and correlated to the results of blood experiments. Otherwise, the velocity fields during the whole pulsatile cycle showed similar profiles despite lower velocities (data are not included in this work).

With the blood experiments, it was possible to investigate the occlusion of an aneurysm after insertion of an FD. The duration of the experiment until thrombus formation was adjusted by anticoagulant concentration. The maximum experiment duration was limited to approximately 12 hours in an attempt to limit the effect of hemolysis, particularly by the use of the pump. Moreover, in the experiments without FDs, no coagulation occurred after the 12-hour test period. Clinical studies report that the aneurysm is never closed by a thrombus at end-of-procedure angiographythat is, after 1 or 2 hours, ${ }^{23,24}$ while at 6-month follow-up angiography, complete occlusion was found in $68 \%-94 \%$ of patients. $^{23,25-31}$ Although it is difficult to judge when the thrombus formation begins in patients, we suppose that the process is strongly accelerated in the in vitro setup, which potentially influences clotting mechanisms.

Dosed anticoagulation by means of Clexane aimed to allow the in vitro use of blood for several hours and does not depict the clinical standard of antiplatelet therapy with aspirin and clopidogrel.

We set both test setups (PIV and blood), with and without FD, to the same flow and pressure conditions and thus neglected the effect of FDs on flow within the parent vessel. In addition, vessel elasticity was neglected by using nearly rigid silicone blocks. Using standardized aneurysm geometry, we did not consider the effect of complex aneurysm geometry on flow pathways.

Our model does not consider the influence of real vessel biology and, in particular, endothelial cells on flow. First, progressive endothelialization of the FD structure would lead to a decrease in pore size. ${ }^{32}$ Second, clotting mechanisms triggered by endothelial cells are not reproduced in the silicone model. By use of FDs, flow deceleration leads to a decrease of shear stress at the aneurysm wall, which is responsible for endothelial cell-induced release of proadhesive and prothrombotic mediators. ${ }^{33}$

In this test series only a limited amount of blood experiments were performed to demonstrate the feasibility of the test setup. To obtain a statistically significant comparison between different FDs, a larger number of experiments are required.

\section{CONCLUSIONS}

In this study, we showed the feasibility of intra-aneurysmal thrombus formation in vitro, comparing 2 different FD sizes with an empty model and correlating the results with PIV measurements. The combination of both methods can potentially im- prove the understanding of the dynamics of thrombus formation. Furthermore, thrombosis investigation in patient-specific models could also support the treatment decision or device-sizing. Potential improvements of the in vitro setup and extensions of this research field are a more detailed life detection of thrombus formation by MR imaging and the development of a transparent and coagulable PIV fluid, such as a modified platelet-rich plasma.

Disclosures: Kathrin Gester, Ines Lüchtefeld, Martin Büsen, Simon Johannes Sonntag, Torsten Linde, Ulrich Steinseifer-RELATED: Grant: This project was funded by the German Federal Ministry for Economic Affairs and Energy.* Giorgio CattaneoRELATED: Grant: Federal Ministry for Economic Affairs and Energy*; UNRELATED: Employment: Acandis GmbH \& Co KG; Grants/Grants Pending: Federal Ministry for Economic Affairs and Energy.* *Money paid to the institution.

\section{REFERENCES}

1. Byrne JV, Beltechi R, Yarnold JA, et al. Early experience in the treatment of intra-cranial aneurysms by endovascular flow diversion: a multicentre prospective study. PLoS One 2010;5:e12492 CrossRef Medline

2. Becske T, Kallmes DF, Saatci I, et al. Pipeline for uncoilable or failed aneurysms: results from a multicenter clinical trial. Radiology 2013; 267:858-68 CrossRef Medline

3. Cebral JR, Mut F, Raschi M, et al. Aneurysm rupture following treatment with flow-diverting stents: computational hemodynamics analysis of treatment. AJNR Am J Neuroradiol 2011;32:27-33 CrossRef Medline

4. Kulcsár Z, Houdart E, Bonafé A, et al. Intra-aneurysmal thrombosis as a possible cause of delayed aneurysm rupture after flow-diversion treatment. AJNR Am J Neuroradiol 2011;32:20-25 CrossRef Medline

5. Pereira VM, Brina O, Delattre BMA, et al. Assessment of intra-aneurysmal flow modification after flow diverter stent placement with four-dimensional flow MRI: a feasibility study. J Neurointerv Surg 2014 Oct 3. [Epub ahead of print] CrossRef Medline

6. Hampton T, Walsh D, Tolias C, et al. Mural destabilization after aneurysm treatment with a flow-diverting device: a report of two cases. J Neurointerv Surg 2011;3:167-71 CrossRef Medline

7. Augsburger L, Farhat M, Reymond P, et al. Effect of flow diverter porosity on intraaneurysmal blood flow. Klin Neuroradiol 2009;19: 204-14 CrossRef Medline

8. Roszelle BN, Gonzalez LF, Babiker MH, et al. Flow diverter effect on cerebral aneurysm hemodynamics: an in vitro comparison of telescoping stents and the Pipeline. Neuroradiology 2013;55:751-58 CrossRef Medline

9. Seong J, Wakhloo AK, Lieber BB. In vitro evaluation of flow diverters in an elastase-induced saccular aneurysm model in rabbit. J Biomech Eng 2007;129:863-72 CrossRef Medline

10. $\mathrm{Yu} \mathrm{CH}$, Matsumoto $\mathrm{K}$, Shida $\mathrm{S}$, et al. A steady flow analysis on a cerebral aneurysm model with several stents for new stent design using PIV. J Mechanical Science and Technology 2012;26:1333-40 CrossRef

11. Bouillot $\mathrm{P}$, Brina $\mathrm{O}$, Ouared $\mathrm{R}$, et al. Particle imaging velocimetry evaluation of intracranial stents in sidewall aneurysm: hemodynamic transition related to the stent design. PLoS One 2014;9: e113762 CrossRef Medline

12. Bouillot $\mathrm{P}, \mathrm{Brina} \mathrm{O}$, Ouared $\mathrm{R}$, et al. Hemodynamic transition driven by stent porosity in sidewall aneurysms. J Biomech 2015;48:1300-09 CrossRef Medline

13. Dorn F, Niedermeyer F, Balasso A, et al. The effect of stents on intraaneurysmal hemodynamics: in vitro evaluation of a pulsatile sidewall aneurysm using laser Doppler anemometry. Neuroradiology 2011;53:267-72 CrossRef Medline

14. Chalouhi N, Starke RM, Yang S, et al. Extending the indications of flow diversion to small, unruptured, saccular aneurysms of the anterior circulation. Stroke 2014;45:54-58 CrossRef Medline

15. Hoi Y, Wasserman BA, Xie YJ, et al. Characterization of volumetric 
flow rate waveforms at the carotid bifurcations of older adults. Physiol Meas 2010;31:291-302 CrossRef Medline

16. Zhao M, Amin-Hanjani S, Ruland S, et al. Regional cerebral blood flow using quantitative MR angiography. AJNR Am J Neuroradiol 2007;28:1470-73 CrossRef Medline

17. Hendrikse J, van Raamt AF, van der Graaf Y, et al. Distribution of cerebral blood flow in the circle of Willis. Radiology 2005;235: 184-89 CrossRef Medline

18. Brown RI. The physics of continuous flow centrifugal cell separation. Artif Organs 1989;13:4-20 CrossRef Medline

19. Ahlhelm F, Roth C, Kaufmann R, et al. Treatment of wide-necked intracranial aneurysms with a novel self-expanding two-zonal endovascular stent device. Neuroradiology 2007;49:1023-28 CrossRef Medline

20. Kallmes DF, Ding YH, Dai D, et al. A new endoluminal, flow-disrupting device for treatment of saccular aneurysms. Stroke 2007;38: 2346-52 CrossRef Medline

21. Simgen A, Ley D, Roth C, et al. Evaluation of a newly designed flow diverter for the treatment of intracranial aneurysms in an elastaseinduced aneurysm model, in New Zealand white rabbits. Neuroradiology 2014;56:129-37 CrossRef Medline

22. Wang K, Huang Q, Hong B, et al. Correlation of aneurysm occlusion with actual metal coverage at neck after implantation of flow-diverting stent in rabbit models. Neuroradiology 2012;54:607-13 CrossRef Medline

23. Wagner A, Cortsen M, Hauerberg J, et al. Treatment of intracranial aneurysms: reconstruction of the parent artery with flow-diverting (Silk) stent. Neuroradiology 2012;54:709-18 CrossRef Medline

24. Fischer S, Vajda Z, Perez MA, et al. Pipeline embolization device (PED) for neurovascular reconstruction: initial experience in the treatment of 101 intracranial aneurysms and dissections. Neuroradiology 2012;54:369-82 CrossRef Medline

25. Lubicz B, Collignon L, Raphaeli G, et al. Flow-diverter stent for the endovascular treatment of intracranial aneurysms: a prospective study in 29 patients with 34 aneurysms. Stroke 2010;41:2247-53 CrossRef Medline

26. Piano M, Valvassori L, Quilici L, et al. Midterm and long-term follow-up of cerebral aneurysms treated with flow diverter devices: a single-center experience. J Neurosurg 2013;118:408-16 CrossRef Medline

27. Saatci I, Yavuz K, Ozer C, et al. Treatment of intracranial aneurysms using the Pipeline flow-diverter embolization device: a single-center experience with long-term follow-up results. AJNR Am J Neuroradiol 2012;33:1436-46 CrossRef Medline

28. Ringelstein A, Schlamann M, Goericke SL, et al. 3-year follow-up after endovascular aneurysm treatment with Silk ${ }^{\circledR}$ flow diverter [in German]. Rofo 2013;185:328-32 CrossRef Medline

29. Cinar C, Bozkaya H, Oran I. Endovascular treatment of cranial aneurysms with the Pipeline flow-diverting stent: preliminary midterm results. Diagn Interv Radiol 2013;19:154-64 CrossRef Medline

30. De Vries J, Boogaarts J, Van Norden A, et al. New generation of flow diverter (Surpass) for unruptured intracranial aneurysms: a prospective single-center study in 37 patients. Stroke 2013;44:1567-77 CrossRef Medline

31. Maimon S, Gonen L, Nossek E, et al. Treatment of intra-cranial aneurysms with the SILK flow diverter: 2 years' experience with 28 patients at a single center. Acta Neurochir (Wien) 2012;154:979-87 CrossRef Medline

32. Kadirvel R, Ding YH, Dai D, et al. Cellular mechanisms of aneurysm occlusion after treatment with a flow diverter. Radiology 2014;270: 394-99 CrossRef Medline

33. Boussel L, Rayz V, McCulloch C, et al. Aneurysm growth occurs at region of low wall shear stress: patient-specific correlation of hemodynamics and growth in a longitudinal study. Stroke 2008;39: 2997-3002 CrossRef Medline 